\title{
Optimal Fiscal Policy Instrument under Different Shocks
}

\author{
Shuguang Xing \\ School of Economics, Peking University, Beijing, China \\ Email: shuguangxing@pku.edu.cn
}

How to cite this paper: Xing, S.G. (2017) Optimal Fiscal Policy Instrument under Different Shocks. Theoretical Economics Letters, 7, 1702-1712.

https://doi.org/10.4236/tel.2017.76115

Received: September 4, 2017

Accepted: October 13, 2017

Published: October 16, 2017

Copyright $\odot 2017$ by author and Scientific Research Publishing Inc. This work is licensed under the Creative Commons Attribution International License (CC BY 4.0).

http://creativecommons.org/licenses/by/4.0/

\begin{abstract}
This paper constructs a New Keynesian model to study optimal tax and government spending rules and compares their welfare. The output gap, inflation and the difference between the output gap and the government spending gap all affect welfare. This paper finds that the optimal fiscal policy instruments under technical shock and cost-push shock are government spending and tax, respectively. If the policymaker is only concerned with the output gap and inflation, the optimal fiscal policy rule and actual social welfare loss will change. However, the optimal fiscal policy instruments under technical shock and cost-push shock are still government spending and tax. This paper also finds that an imperfect financial market affects social welfare but does not change the optimal fiscal policy instrument under different shocks.
\end{abstract}

\section{Keywords}

Social Welfare, Tax, Government Spending

\section{Introduction}

After the financial crisis broke out in 2008, the world economy sank into recession and many countries adopted proactive fiscal policies to stimulate the economy. Between increasing government spending and cutting taxes, which is more effective? Many scholars establish DSGE models to compare the effects of tax and government spending. Denes and Eggertsson [1] and Eggertsson [2] argue that when the nominal short-term interest rate is zero, a tax cut leads to deflation, which in turn increases recession, while increasing government spending is more effective. Erceg and Linde [3] study the effect of increasing taxes and decreasing government spending on output to meet fiscal constraints in a monetary union. Given the limited scope for monetary accommodation, raising taxes has a smaller adverse effect on output compared to cutting government spending in the short 
term but has a bigger adverse effect in the long term. If the interest rate is close to zero, the impact of cutting government spending on output increases.

Most related empirical studies use SVAR models. Blanchard and Perotti [4] find increasing government spending has a positive effect on output, and increasing taxes has a negative effect, and they both have a negative effect on investment spending. Mountford and Uhlig [5] and Caldara and Kamps [6] find that the multiplier of tax cuts is greater than that of increasing government spending. Batini et al. [7] find that in order to meet fiscal constraints, increasing taxes has a less adverse effect on output than cutting government spending. In addition, Arin et al. [8], using Bayesian model averaging, find that productive public spending has a positive effect on output, while top corporate tax rates have a negative effect, and fiscal variables with no robust effect on output include top income tax rates, government consumption, and distortionary taxes.

The studies are only concerned with the effect of fiscal policy on output. However, what affects social welfare includes not only output but also inflation and other things. What is more, they ignore the different effects of fiscal policy under different shocks. This paper constructs a simple New Keynesian model to study optimal fiscal instruments under different shocks. In contrast with Woodford [9], the welfare loss function in this paper includes not only the output gap and inflation but also the difference between the output gap and the government spending gap. The optimal tax and government spending rules are given and their welfare losses are compared. Tax can stabilize cost-push shock, but not technology shock, while government spending can stabilize technology shock, but not cost-push shock. This means that the optimal fiscal policy instrument under technical shock is government spending, and the optimal fiscal policy instrument under cost-push shock is tax.

If a policymaker is only concerned with the output gap and inflation, tax and government spending will eliminate the effects of cost-push shock and technology shock on marginal costs and then further eliminate the output gap and inflation. However, the actual welfare loss increases when using tax (government spending) to stabilize technology (cost-push) shock.

Finally, this paper assumes that households cannot access the financial market. In this case, the optimal fiscal policy instruments under technical shock and cost-push shock are still the government spending and tax respectively, and both they can achieve the effective allocation.

This paper is organized as follows. Section 2 constructs a New Keynesian model. Section 3 log-linearizes the welfare function and constraint conditions. Section 4 considers the optimal tax rule and the optimal government spending rule and compares their welfare. Section 5 analyzes the impact of imperfect financial markets on fiscal rules and social welfare. Section 6 is the conclusion.

\section{Model}

According to traditional New Keynesian model, the households are evenly dis- 
tributed in the $[0,1]$ interval. Each household is both a consumer and a producer. The product market is monopoly competition. Firms are owned by households. In addition, households have access to perfect financial markets.

Each household has the same preference. Suppose that the elasticity of the intertemporal substitution of consumption and the wage elasticity of labor supply are both 1 . The representative household maximizes the utility function:

$$
E \sum_{t=0}^{\infty} \beta^{t}\left[\chi \ln C_{t}+(1-\chi) \ln G_{t}-L_{t}\right]
$$

where $E$ is the expectation, $\beta$ is the discount factor, $C_{t}$ is the consumption index, $L_{t}$ is the labor time, $\chi$ is the ratio of consumption to government expenditure in utility. This form of utility function is easy for us to derive the second-order welfare loss function.

The budget constraint of household is:

$$
P_{t} C_{t}+E_{t} Q_{t, t+1} D_{t+1} \leq W_{t} L_{t}+D_{t}+\Pi_{t}-P_{t} \Gamma_{t}
$$

where $P_{t}$ is the price level, $D_{t+1}$ is the nominal return on the asset held by the household in period $t+1, Q_{t, t+1}$ is the random discount factor, $W_{t}$ is the nominal wage, $\Pi_{t}$ is the firm's profit, $\Gamma_{t}$ is the lump tax. Household consumption $C_{t}$ is a set of products with differentiated products, $C_{t} \equiv\left[\int_{0}^{1} C_{t}(i)^{(\theta-1) / \theta} \mathrm{d} i\right]^{\theta /(\theta-1)}$, defined by Dixit and Stiglitz [10], and $\theta>1$ is the elasticity of the product substitution.

Under the budget constraint and transversal condition $\lim _{T \rightarrow \infty} E_{t}\left(Q_{t T} D_{T}\right)=0$, the optimal labor supply equation can be obtained by maximizing the utility function:

$$
\chi \frac{W_{t}}{P_{t}} \frac{1}{C_{t}}=1
$$

Equation (3) shows that the positive marginal utility of increasing labor supply is just equal to its negative marginal utility. We can also get the Euler equation:

$$
\frac{1}{C_{t}}=\beta E_{t}\left(\frac{1}{C_{t+1}} \frac{P_{t}}{P_{t+1}} R_{t}\right)
$$

where $R_{t} \equiv\left(E_{t} Q_{t, t+1}\right)^{-1}$. Equation (4) reflects the optimal consumption path.

Consistent with the traditional New Keynesian model, capital is not considered here. There is a continuum of monopoly firms represented by the interval $[0,1]$. The product function is:

$$
Y_{t}(i)=A_{t} L_{t}(i)
$$

where $Y_{t}(i)$ is the product of firm $i$ in period $t, L_{t}(i)$ is the labor demand, $A_{t}$ is the level of technology, assumed to be common to all firms and to evolve exogenously over time. Following Calvo [11], the firm resets price $P_{t}(i)$ with a constant probability, $1-\alpha$, in each period to maximize the expected profit: 


$$
E_{t} \sum_{T=t}^{\infty} \alpha^{T-t} Q_{t, T}\left[\left(1-\tau_{T}\right) P_{t}(i) Y_{T}(i)-(1-\eta) W_{T} L_{T}(i)\right]
$$

where $\tau_{t}$ is the sales tax rate, $\eta$ is the government subsidies at steady state to eliminate the monopoly distortion. The first-order condition for this optimal problem is:

$$
E_{t} \sum_{T=t}^{\infty} \alpha^{T-t} Q_{t, T}\left[\left(1-\tau_{T}\right)\left(\frac{P_{t}(i)}{P_{T}}\right)^{-\theta} Y_{T}-\mu(1-\eta) W_{T}\left(P_{t}(i)\right)^{-\theta-1}\left(P_{T}\right)^{\theta} \frac{Y_{T}}{A_{T}}\right]=0
$$

where $\mu \equiv \frac{\theta}{\theta-1}$, denotes price markup. $Y_{t}$ is the output, defined as $Y_{t} \equiv\left[\int_{0}^{1} Y_{t}(i)^{(\theta-1) / \theta} \mathrm{d} i\right]^{\theta /(\theta-1)}$.

Calvo pricing means the price follows the rule:

$$
P_{t}=\left[\alpha P_{t-1}^{1-\theta}+(1-\alpha) P_{t}(i)^{1-\theta}\right]^{1 /(1-\theta)}
$$

\section{Log-Linearization}

Log-linearization first requires determining the steady-state value of each variable. In the steady state, there are no exogenous shocks. Assume $A=1$, so $Y=L$. Social planner maximizes the welfare function $\chi \ln C+(1-\chi) \ln G-L$, under resource constraint $Y=C+G$. The optimal steady state values are $Y=1$, $C=\chi, G=1-\chi$. Social planner at the steady state eliminates monopoly distortion through subsidy.

When the price is flexible, $L_{t}=1, Y_{t}=A_{t}, C_{t}=\chi A_{t}, G_{t}=(1-\chi) A_{t}$. If there is no monopoly distortion under flexible price, a decentralized economy can achieve the effective allocation.

Define $\hat{X}_{t} \equiv \log \left(X_{t} / X\right), \quad \hat{X}_{t}$ denotes the log-deviation of $X_{t}$ from its steady state $X$ under sticky price; Define $\hat{X}_{t}^{n} \equiv \log \left(X_{t}^{n} / X\right), \hat{X}_{t}^{n}$ denotes the logdeviation of $X_{t}$ from its steady state $X$ under flexible price; Define $\tilde{X}_{t} \equiv \hat{X}_{t}-\hat{X}_{t}^{n}$, $\tilde{X}_{t}$ denotes the gap between $\hat{X}_{t}$ and its natural rate $\hat{X}_{t}^{n}$. Then, we have $\hat{Y}_{t}^{n}=\hat{A}_{t}, \quad \hat{C}_{t}^{n}=\hat{A}_{t}, \quad \hat{G}_{t}^{n}=\hat{A}_{t}$.

When the price is sticky, the welfare loss function can be obtained by the second-order approximation method of Woodford [10]:

$$
\bar{W}=-\frac{1}{2} E_{0} \sum_{t=0}^{\infty} \beta^{t}\left[\tilde{Y}_{t}^{2}+\frac{\theta}{k} \pi_{t}^{2}+\frac{1-\chi}{\chi}\left(\tilde{Y}_{t}-\tilde{G}_{t}\right)^{2}\right]+t i p+O\left(\|\xi\|^{3}\right)
$$

where tip is the terms independent of policy including constants and functions of exogenous shocks, $O\left(\|\xi\|^{3}\right)$ stands for the terms that are of order higher than the second, $k \equiv \frac{(1-\alpha)(1-\alpha \beta)}{\alpha}, \tilde{Y}_{t} \equiv \hat{Y}_{t}-\hat{A}_{t}, \pi_{t}$ is inflation. The larger the output gap or inflation, the smaller the welfare. $\frac{1-\chi}{\chi}\left(\tilde{Y}_{t}-\tilde{G}_{t}\right)^{2}$ reflects the second-order effect of government spending crowding out consumption. When $\chi=1$, the welfare loss function is consistent with Woodford [9]. 
Log-linearizing optimal pricing rule can obtain the New Keynesian Phillips curve:

$$
\pi_{t}=k\left(\frac{1}{\chi} \tilde{Y}_{t}-\frac{1-\chi}{\chi} \tilde{G}_{t}+\frac{1}{\theta} \hat{\tau}_{t}+\hat{\mu}_{t}\right)+\beta E_{t} \pi_{t+1}
$$

where $\hat{\mu}_{t}$ denotes the cost-push shock. An increase in output increases labor demand and leads to an increase in wage, which in turn increases marginal cost and inflation. The smaller the price stickiness, the larger $k$, then the higher the inflation caused by the increase in output. Increasing the tax rate raises the marginal cost and increases inflation. Given the output, government spending will crowd out consumption. According to Equation (3), the real wage will fall, which will reduce inflation. When firms expect an increase in inflation, they raise prices, which in turn leads to inflation.

Log-linearizing Euler equation can obtain the New Keynesian IS curve:

$$
\tilde{Y}_{t}=E_{t} \tilde{Y}_{t+1}-\chi\left(i_{t}-E_{t} \pi_{t+1}-i-E_{t} \Delta \hat{A}_{t+1}\right)-(1-\chi) E_{t} \Delta \tilde{G}_{t+1}
$$

where $i \equiv 1 / \beta-1$. When the interest rate rises, current consumption declines, resulting in a decline in output. Meanwhile, increasing government spending will lead to higher output.

\section{Optimal Fiscal Policy}

If both tax and government spending can be used, efficient allocation will be achieved. Then, $\tilde{Y}_{t}=0, \pi_{t}=0, \tilde{G}_{t}=0, \hat{\tau}_{t}=-\theta \hat{\mu}_{t}, i_{t}=i+E_{t} \Delta \hat{A}_{t+1}$. The following analyzes the optimal tax and government spending rules.

\subsection{Optimal Tax Rule}

Under the constraints of Equations ((10) and (11)), the central bank and fiscal authority choose $\left\{\tilde{Y}_{t}, \pi_{t}, i, \hat{\tau}_{t}\right\}$ to the maximize welfare loss function Equation (9). The optimal tax and monetary rules are:

$$
\begin{gathered}
\tilde{Y}_{t}=-(1-\chi) \hat{A}_{t} \\
\pi_{t}=0 \\
\hat{\tau}_{t}=-\theta \hat{\mu}_{t} \\
i_{t}=i+E_{t} \Delta \hat{A}_{t+1}
\end{gathered}
$$

From Equation (14), we know that tax does not change under technology shock, but decreases with the increase of cost-push shock to completely eliminate the impact of cost-push shock on marginal cost. When there is a technology shock, the tax rule is $\hat{\tau}_{t}=0$, and the interest rate rule is $i_{t}=i+E_{t} \Delta \hat{A}_{t+1}$. Then, $\pi_{t}=0, \tilde{Y}_{t}=-(1-\chi) \hat{A}_{t}$. Because the fiscal instrument is tax, so $\hat{G}_{t}=0$, then $\tilde{G}_{t}=-\hat{A}_{t}$. So $\tilde{Y}_{t} \neq 0, \tilde{Y}_{t}-\tilde{G}_{t} \neq 0$, that means tax cannot stabilize the technology shock. When there is a cost-push shock, the tax rule is $\hat{\tau}_{t}=-\theta \hat{\mu}_{t}$, and the interest rate rule is $i_{t}=i$. Then, $\tilde{Y}_{t}=0, \pi_{t}=0, \tilde{G}_{t}=0$, that means tax can stabilize the cost-push shock, and achieve the effective allocation. 


\subsection{Optimal Government Spending Rule}

Under the constraints of Equations ((10) and (11)), the central bank and fiscal authority choose $\left\{\tilde{Y}_{t}, \pi_{t}, i_{t}, \tilde{G}_{t}\right\}$ to the maximize welfare loss function. The optimal government spending and monetary rules are:

$$
\begin{gathered}
\tilde{Y}_{t}=\varpi \beta E_{t} \tilde{Y}_{t+1}+\varpi \tilde{Y}_{t-1}-\varpi \theta k \hat{\mu}_{t} \\
\pi_{t}=-\frac{1}{\theta} \Delta \tilde{Y}_{t} \\
\tilde{G}_{t}=0 \\
i_{t}=i+\left(1-\frac{\theta}{\chi}\right) E_{t} \pi_{t+1}+E_{t} \Delta \hat{A}_{t+1}
\end{gathered}
$$

where $\varpi \equiv \frac{\chi}{(1+\beta) \chi+\theta k}$. Under a technology shock, government spending can achieve the effective allocation, that means $\tilde{Y}_{t}=0, \pi_{t}=0, \tilde{G}_{t}=0$. The interest rate rule is $i_{t}=i+E_{t} \Delta \hat{A}_{t+1}$. Under a cost-push shock, $\tilde{Y}_{t}$ and $\pi_{t}$ are not zero, the effective allocation cannot be achieved. Meanwhile, $\hat{G}_{t}=\tilde{G}_{t}=0$, $i_{t}=i+\left(1-\frac{\theta}{\chi}\right) E_{t} \pi_{t+1}$.

\subsection{Simulation}

To more intuitively compare the welfare losses of tax and government spending, this paper will conduct simulations. All the parameter values are commonly used in the literature. The discount rate $\beta$ is 0.99 , the elasticity of product substitution $\theta$ is 11 , the price stickiness index $\alpha$ is 0.8 , the share of consumption in output in steady state $\chi$ is 0.7 in the steady state, and the tax rate in the steady state $\tau$ is 0.3 . The shocks are AR (1) processes with autoregressive coefficient 0.9 and innovation variance 0.01 . The simulation software is Dynare 4.4 .3 running with MATLAB 2013.

According to Woodford [9] and Gali [12], welfare loss can be expressed as:

$$
\bar{W}=\frac{1}{2}\left(\operatorname{var}\left(\tilde{Y}_{t}\right)+\frac{\theta}{k} \operatorname{var}\left(\pi_{t}\right)+\frac{1-\chi}{\chi} \operatorname{var}\left(\tilde{Y}_{t}-\tilde{G}_{t}\right)\right)
$$

where $\operatorname{var}(X)$ denotes the variance of $X$.

Table 1 shows the welfare losses under technology shock and cost-push shock. Consistent with the above analysis, government spending can fully stabilize technology shock to achieve effective allocation, and the welfare loss is zero. If tax is used to stabilize technology shock, the welfare loss is 0.0079 . That means welfare loss accounts for $0.79 \%$ of output in the steady state. The output gap, inflation, and the difference between the output gap and the government spending gap cause welfare loss by $0.0024,0$, and 0.0055 , respectively. This case is the same as in the absence of fiscal policy, and tax under technology shock is superfluous.

Tax can fully stabilize the cost-push shock with zero welfare loss. If government spending is used to stabilize cost-push shock, the welfare loss is 0.0161 , 
which accounts for $1.61 \%$ of output in steady-state. The output gap, inflation, and the difference between the output gap and the government spending gap cause welfare loss by $0.0102,0.0015$, and 0.0044 , respectively. That is, the same as in the absence of tax under technology shock.

\subsection{Alternative Welfare Objective}

Equation (9) shows that welfare loss is caused by $\tilde{Y}_{t}, \pi_{t}$ and $\tilde{Y}_{t}-\tilde{G}_{t}$ three parts. What occurs if a policymaker is only concerned about the output gap and inflation? The welfare loss function in this case is:

$$
\bar{W}=-\frac{1}{2} E_{0} \sum_{t=0}^{\infty} \beta^{t}\left(\tilde{Y}_{t}^{2}+\frac{\theta}{k} \pi_{t}^{2}\right)+t i p+O\left(\|\xi\|^{3}\right)
$$

The central bank and fiscal authority choose $\left\{\tilde{Y}_{t}, \pi_{t}, i, \hat{\tau}_{t}\right\}$ and $\left\{\tilde{Y}_{t}, \pi_{t}, i_{t}, \tilde{G}_{t}\right\}$ to maximize welfare loss function (21) under the constraints of Equations ((10) and (11)). The optimal path of each variable under tax policy is: $\tilde{Y}_{t}=0, \pi_{t}=0$, $\hat{\tau}_{t}=-\frac{(1-\chi) \theta}{\chi} \hat{A}_{t}-\theta \hat{\mu}_{t}, i_{t}=i+E_{t} \Delta \hat{A}_{t+1}$. In this case, tax decrease with the increasing of technology shock and cost-push shock to offset their effects on the marginal cost. The optimal path of each variable under government spending policy is: $\tilde{Y}_{t}=0, \pi_{t}=0, \tilde{G}_{t}=\frac{\chi}{1-\chi} \hat{\mu}_{t}, i_{t}=i+E_{t} \Delta \hat{A}_{t+1}-E_{t} \Delta \hat{\mu}_{t+1}$. Government spending can eliminate the output gap and inflation.

As shown in Table 2, although the output gap and inflation both are zero, the real welfare loss function expressed as Equation (20) is worse when using government spending to stabilize cost-push shock or using tax to stabilize technology

Table 1. Welfare Losses.

\begin{tabular}{cccccc}
\hline & & $\tilde{Y}_{t}$ & $\pi_{t}$ & $\tilde{Y}_{t}-\tilde{G}_{t}$ & Total \\
\hline $\begin{array}{c}\text { Government } \\
\text { Spending }\end{array}$ & Technology shock & 0 & 0 & 0 & 0 \\
Cost-push shock & 0.0102 & 0.0015 & 0.0044 & 0.0161 \\
Tax & Technology shock & 0.0024 & 0 & 0.0055 & 0.0079 \\
No Fiscal Policy & Cost-push shock & 0 & 0 & 0 & 0 \\
& Technology shock & 0.0024 & 0 & 0.0055 & 0.0079 \\
\hline
\end{tabular}

Notes: The values in the third, fourth and fifth column are welfare losses caused by $\tilde{Y}_{t}$, $\pi_{t}$, and $\tilde{Y}_{t}-\tilde{G}_{t}$, respectively. The values in the sixth column are the total Welfare losses. The same below.

Table 2. Welfare Losses Under Alternative Welfare Objective.

\begin{tabular}{cccccc}
\hline & & $\tilde{Y}_{t}$ & $\pi_{t}$ & $\tilde{Y}_{t}-\tilde{G}_{t}$ & Total \\
\hline \multirow{2}{*}{ Government } & Technology shock & 0 & 0 & 0 & 0 \\
Spending & Cost-push shock & 0 & 0 & 0.0614 & 0.0614 \\
& Technology shock & 0 & 0 & 0.0113 & 0.0113 \\
Tax & Cost-push shock & 0 & 0 & 0 & 0 \\
\hline
\end{tabular}


shock. However, the optimal fiscal policy instruments for technology shocks and cost-push shocks are still government spending and tax, respectively.

\section{Imperfect Financial Market}

As per Gali et al. [13], this paper will analyze households without access to the financial market. The households cannot use bonds to smooth consumption as before. The budget constraint of households is:

$$
P_{t} C_{t}=W_{t} L_{t}
$$

From Equations ((3) and (22)), we can get:

$$
L_{t}=\chi
$$

Equation (23) means if households cannot access the financial market, labor supply is constant. We get:

$$
\hat{Y}_{t}=\hat{A}_{t}, \tilde{Y}_{t}=0
$$

The welfare loss function under an imperfect financial market is:

$$
\bar{W}=-\frac{1}{2} E_{0} \sum_{t=0}^{\infty} \beta^{t}\left(\frac{\theta}{k} \pi_{t}^{2}+\frac{1-\chi}{\chi} \tilde{G}_{t}^{2}\right)+t i p+O\left(\|\xi\|^{3}\right)
$$

The New Keynesian Phillips curve is:

$$
\pi_{t}=k\left(-\frac{1-\chi}{\chi} \tilde{G}_{t}+\frac{1}{\theta} \hat{\tau}_{t}+\hat{\mu}_{t}\right)+\beta E_{t} \pi_{t+1}
$$

The central bank and the fiscal authority choose $\left\{\pi_{t}, \hat{\tau}_{t}\right\}$ and $\left\{\pi_{t}, \tilde{G}_{t}\right\}$ to the maximize welfare loss function (25) under the constraint of (26). The optimal path of each variable under the optimal tax policy is: $\tilde{Y}_{t}=0, \pi_{t}=0$, $\hat{\tau}_{t}=-\frac{(1-\chi) \theta}{\chi} \hat{A}_{t}-\theta \hat{\mu}_{t}, \quad \tilde{G}_{t}=-\hat{A}_{t}$. As in the perfect financial market, tax can stabilize cost-push shock, but not technology shock.

When the fiscal instrument is government spending, the optimal government spending rule is:

$$
\tilde{G}_{t}=\omega \beta E_{t} \tilde{G}_{t+1}+\omega \tilde{G}_{t-1}+\omega \theta k \hat{\mu}_{t}
$$

where $\omega \equiv \frac{\chi}{(1-\chi) k \theta+(1+\beta) \chi}$.

The inflation target is:

$$
\pi_{t}=\frac{1}{\theta} \Delta \tilde{G}_{t}
$$

From Equations ((27) and (28)), we can get $\tilde{G}_{t}=0, \pi_{t}=0$, under technology shock, but $\tilde{G}_{t} \neq 0, \pi_{t} \neq 0$, under technology shock. So as in the perfect financial market, government spending can stabilize technology shock, but not cost-push shock.

Table 3 presents the simulation results under an imperfect financial market. Consistent with the previous analysis, if households cannot access the financial 
Table 3. Welfare Losses Under the Imperfect Financial Market.

\begin{tabular}{cccccc}
\hline & & $\tilde{Y}_{t}$ & $\pi_{t}$ & $\tilde{Y}_{t}-\tilde{G}_{t}$ & Total \\
\hline Government & Technology shock & 0 & 0 & 0 & 0 \\
Spending & Cost-push shock & 0 & 0.0077 & 0.0382 & 0.0459 \\
\multirow{2}{*}{ Tax } & Technology shock & 0 & 0 & 0.0113 & 0.0113 \\
& Cost-push shock & 0 & 0 & 0 & 0 \\
\hline
\end{tabular}

market, the optimal fiscal policy instruments under technology shock and cost-push shock are government spending and taxation. What is more, government spending (tax) harms social welfare under cost-push (technology) shock.

\section{Conclusions}

Many studies compare the difference between the tax multiplier and government spending multiplier, but they only focus on the effect of fiscal policy on output, not on social welfare. In addition, these studies also ignore that the effects of fiscal policy are different under different shocks. In this paper, a simple New Keynesian model is established to study the optimal tax and government spending rules and compares their welfare difference. This paper finds that the optimal fiscal policy instruments under technical shock and cost-push shock are government spending and tax, respectively. The factors affecting social welfare include the output gap, inflation, and the difference between the output gap and the government spending gap. If the policymaker is only concerned with the output gap and inflation, the actual social welfare loss will change. However, the optimal fiscal policy instruments under technical shock and cost-push shock are still government spending and tax, respectively. Finally, this paper assumes that households cannot access the financial market. In this case, the optimal fiscal policy instrument under different shocks does not change.

There are rooms of improvement in this paper. In order to simplify the model, this paper sets the relative risk aversion coefficient to one, and a general utility function can be set up in the future. In addition, this paper does not consider fiscal budget, and government sector can be introduced into the model. Finally, interest rate in many developed countries approaches to zero, and this means fiscal policy is more important, and we can study the optimal fiscal instrument in this case.

\section{References}

[1] Denes, M. and Eggertsson, G.B. (2009) A Bayesian Approach to Estimating Tax and Spending Multipliers. FRB of New York Staff Report 403. https://doi.org/10.2139/ssrn.1504845

[2] Eggertsson, G.B. (2011) What Fiscal Policy Is Effective at Zero Interest Rates? NBER Macroeconomics Annual, 25, 59-112. https://doi.org/10.1086/657529

[3] Erceg, C.J. and Linde, J. (2013) Fiscal Consolidation in a Currency Union: Spending Cuts vs. Tax Hikes. Journal of Economic Dynamics and Control, 37, 422-445. 
https://doi.org/10.1016/j.jedc.2012.09.012

[4] Blanchard, O. and Perotti, R. (2002) An Empirical Characterization of the Dynamic Effects of Changes in Government Spending and Taxes on Output. The Quarterly Journal of Economics, 117, 1329-1368. https://doi.org/10.1162/003355302320935043

[5] Mountford, A. and Uhlig, H. (2009) What Are the Effects of Fiscal Policy Shocks? Journal of Applied Econometrics, 24, 960-992. https://doi.org/10.1002/jae.1079 http://onlinelibrary.wiley.com/doi/10.1002/jae.1079/full

[6] Caldara, D. and Kamps, C. (2012) The Analytics of SVARs: A Unified Framework to Measure Fiscal Multipliers. Board of Governors of the Federal Reserve System WP.

[7] Batini, N., Callegari, G. and Melina, G. (2012) Successful Austerity in the United States, Europe and Japan. IMF Working Paper WP/12/190.

[8] Arin, K.P., Braunfels, E. and Doppelhofer, G. (2015) Taxes, Spending and Economic Growth: A Bayesian Model Averaging Approach. Cesifo WP.

[9] Woodford, M. (2003) Interest and Prices: Foundations of a Theory of Monetary Policy. Princeton University Press, Princeton.

[10] Dixit, A. and Stiglitz, J. (1977) Monopolistic Competition and Optimum Product Diversity. American Economic Review, 67, 297-308.

[11] Calvo, G. (1983) Staggered Prices in a Utility Maximizing Framework. Journal of Monetary Economics, 12, 383-395. https://doi.org/10.1016/0304-3932(83)90060-0

[12] Gali, J. (2008) Monetary Policy, Inflation, and the Business Cycle: An Introduction to the New Keynesian Framework. Princeton University Press, Princeton.

[13] Gali, J., Lopez-Salido, J.D. and Valles, J. (2007) Understanding the Effects of Government Spending on Consumption. Journal of the European Economic Association, 5, 227-270. http://onlinelibrary.wiley.com/doi/10.1162/JEEA.2007.5.1.227/full https://doi.org/10.1162/JEEA.2007.5.1.227 


\section{Appendix A: Log-Linearization of Welfare Objective}

Taking second-order approximations to the representative household's utility function, we can get:

$$
\begin{aligned}
U_{t}= & \chi \ln C_{t}+(1-\chi) \ln G_{t}-L_{t} \\
= & \chi \frac{C_{t}-C}{C}-\frac{\chi}{2} \frac{\left(C_{t}-C\right)^{2}}{C^{2}}+(1-\chi) \frac{G_{t}-G}{G} \\
& -\frac{(1-\chi)}{2} \frac{\left(G_{t}-G\right)^{2}}{G^{2}}-L \frac{L_{t}-L}{L}+t i p+O\left(\|\xi\|^{3}\right) \\
= & \chi \hat{C}_{t}+(1-\chi) \hat{G}_{t}-L\left(\hat{L}_{t}+\frac{1}{2} \hat{L}_{t}^{2}\right)+t i p+O\left(\|\xi\|^{3}\right)
\end{aligned}
$$

From the firm's production function, we can get:

$$
L_{t}=\frac{Y_{t} \Delta_{t}}{A_{t}}
$$

where $\Delta_{t} \equiv \int_{0}^{1}\left[\frac{P_{t}(i)}{P_{t}}\right]^{-\theta} \mathrm{d} i$, denotes the price dispersion.

(A.2) can be log-linearized as:

$$
\hat{L}_{t}=\hat{Y}_{t}+\hat{\Delta}_{t}-\hat{A}_{t}
$$

According to (A.3), (A.1) can be rewritten as:

$$
U_{t}=\chi \hat{C}_{t}+(1-\chi) \hat{G}_{t}-\left(\hat{\Delta}_{t}+\hat{Y}_{t}+\frac{1}{2}\left(\hat{Y}_{t}-\hat{A}_{t}\right)^{2}\right)+t i p+O\left(\|\xi\|^{3}\right)
$$

The market clearing condition is:

$$
Y_{t}=C_{t}+G_{t}
$$

Above equation can be log-linearized as:

$$
\hat{C}_{t}=\frac{1}{\chi} \hat{Y}_{t}-\frac{1-\chi}{\chi} \hat{G}_{t}-\frac{1-\chi}{2 \chi^{2}}\left(\hat{Y}_{t}-\hat{G}_{t}\right)^{2}
$$

According to Woodford (2003), we have:

$$
\sum_{t=0}^{\infty} \beta^{t} \hat{\Delta}_{t}=\frac{1}{2} \frac{\alpha \theta}{(1-\alpha)(1-\alpha \beta)} \sum_{t=0}^{\infty} \beta^{t} \pi_{t}^{2}+t i p+O\left(\|\xi\|^{3}\right)
$$

According to (A.4), (A.6) and (A.7), social welfare can be rewritten as:

$$
\bar{W}=-\frac{1}{2} E_{0} \sum_{t=0}^{\infty} \beta^{t}\left[\left(\hat{Y}_{t}-\hat{A}_{t}\right)^{2}+\frac{\theta}{k} \pi_{t}^{2}+\frac{1-\chi}{\chi}\left(\hat{Y}_{t}-\hat{G}_{t}\right)^{2}\right]+t i p+O\left(\|\xi\|^{3}\right)
$$

Since the definition $\tilde{X}_{t} \equiv \hat{X}_{t}-\hat{X}_{t}^{n}$, and $\hat{Y}_{t}^{n} \equiv \hat{A}_{t}$, (A.8) can be rewritten as:

$$
\bar{W}=-\frac{1}{2} E_{0} \sum_{t=0}^{\infty} \beta^{t}\left[\tilde{Y}_{t}^{2}+\frac{\theta}{k} \pi_{t}^{2}+\frac{1-\chi}{\chi}\left(\tilde{Y}_{t}-\tilde{G}_{t}\right)^{2}\right]+t i p+O\left(\|\xi\|^{3}\right)
$$

